\title{
O RISCO DE D. QUIXOTE \\ - SABER E NÃO SABER, É E NÃO É -
}

\section{THE RISK OF D. QUIJOTE \\ - KNOWING AND NOT KNOWING, IT IS AND IS NOT -}

\author{
Marcus Alexandre Motta \\ Universidade do Estado do Rio de Janeiro, Instituto de Letras, \\ Rio de Janeiro, RJ, Brasil
}

Resumo: Este texto sugere um tipo de crítica às gradaçóes da "teleologia", que se manifestam na escrita especializada. Para tanto, assume o risco de D. Quixote, acentuado o teatro tipográfico ao qual, querendo ou não, todos estamos submetidos.

Palavras-chave: tipografia; saber; risco; loucura; história.

Abstract: This text suggests a kind of criticism to the "teleology" gradations, manifested in the specialized writing. Thus, it assumes the risk of Don Quixote, emphasizing the typographic theater to which, like it or not, we are all subjected.

Keywords: typography; knowledge; risk; madness; history.

Trago comigo, náo poderia ser de outro modo, o demônio da perversidade. Aquele de Poe - "penso, portanto me destruo". No caso de dizer, "estou seguro", é isso mesmo que destrói a minha segurança e desmente o que eu disse. Descobre-se aí, nada há que possa evitar, o demônio das palavras, implantado nelas, e, elas, "vivendo suas próprias vidas, mirando-nos de soslaio, invocando-se mutualmente, abandonandonos [...]" (CAVELL, 2002, p. 204).

Estar aqui; tão próximo. Em risco, e não. Acabo de lembrar dos "seus textos", "seus estudos de literatura". Li dantes. Li depois. Li e me distraí e logo chegaram. Chegaram as muitas conformaçôes da palavra fim nos discursos, em sua grande maioria. Retumbam as gradaçóes da "teleologia", no sentido lato do termo (não é?). Manifestam-se como escrita especializada, ora por caráter historicista, declinando um tipo de partida ou chegada para 
pensamento, demarcando um tempo vazio e homogêneo preenchido por explicaçóes que acalmam as tensóes da história, ora através do formismo, reivindicando a ascendência aristotélica para a categorizaçáo dos conceitos (grave confusão lógica), numa aplicabilidade nunca vista. "Tudo para atrairnos com a ideia primária de que todas as épocas são iguais ou de que são diferentes" (BORGES, 1988, p. 493).

Sinto-me afortunado e traído pela ocasiáo. Mas o que me chega, não me deixa. Esqueço momentaneamente. "O escorrer da língua é o que conta. Os pensamentos. Solene” (JOYCE, 1996, p. 117). E ali, de além, de aquém, soa para todos os arrebatamentos dos momentos aisthesis que nunca se deixam calar quando escrevemos e nos ameaçam.

Estou às voltas com ideias e sensaçôes; desatinado sem ocasião e dando-me a entender, portanto. Experimento, assim, alguns estalos e saltos da loucura (perigosa palavra e sem outra que esteja aos pés), como obsessão de ler literariamente. Leio-os, lembro, e aspiro D. Quixote - "seguia com seu romance em resposta a quanto se lhe perguntava" (CERVANTES, 2005 p.75).

Nele e por ele, a imputabilidade poética perpetra regressar a loucura ao nosso lugar não-lugar da linguagem. Faz, porém, não voltar de uma vez por todas. Tão-só em cada risco de pensamento. Como uma forma de chegar indiretamente mais perto das erupçóes das artes do literário.

Toda a Arte é uma forma de literatura, porque toda arte é dizer qualquer coisa. Há duas formas de dizer - falar e estar calado. As artes que náo são a literatura são as projeçôes de um silêncio expressivo. Há que procurar em toda a arte que não é a literatura a frase silenciosa que ela contém, ou o poema, ou o romance, ou drama. Quando se diz 'poema sinfônico' falase exatamente e não de um modo translato e fácil. O caso parece menos simples para as artes visuais, mas, se nos prepararmos com a consideraçáo de que linhas, planos, volumes, cores, justaposiçóes e contraposiçôes são fenômenos verbais dados sem palavras, ou antes por hieróglifos espirituais, compreenderemos como compreender as artes visuais, e, ainda que náo as cheguemos a compreender ainda, teremos, ao menos, já em nosso poder o livro que contém a cifra e a alma que pode conter a decifração. Tanto basta até chegar o resto (PESSOA, 1998, p. 261).

Desejo de assentir nos termos daquela tarefa. Tudo linguagem, a única forma de vida (o sublinhar apenas sob a primeira palavra, ao contrário de Wittgenstein). Em todas as artes há uma forma de Literatura. Acendido risco! Loucura! O saber que é e não é. A responsabilidade é enorme.

Nesse caso, somos, ou devíamos ser, as inscriçôes da solidão na página 
pobre (para que arte tenha alguma chance); ermos e findos. Ali, aspirar qualquer retorno. D. Quixote continuamente. Ali, talvez, ensaiar (marca de nossa tarefa herdada) o testemunho, algo contra, as inteligências eficientes, afinando as palavras com outras coisas que li.

A maioria das abrandadas exposiçóes que me chegam, digo, já numa distância respeitosa e atenta (ou numa proximidade radical que eu não daria por mim), vai abandonando o literário e vai esquecendo haver teatro tipográfico. Há e não há. "As obras de arte são uma escrita, e não apenas as que parecem como tais, e certamente hieroglíficas, para quais se perdeu o código e para cujo conteúdo contribuiu acima de tudo a ausência de tal código" (ADORNO, 1993, p 145).

Teatro tipográfico. Em todo caso, tudo é escrita e ausência de código. Escrita gatafunhada, aquela que vem de Klee. Tipografia do inquietante, da lógica do mito, do sonho, do esgarçar da verossimilhança - literatura (em todas as artes ela está, e, elas, nela), desde sempre, apesar de Platáo e todos os saneamentos da linguagem, apesar de todas eficiências e de todas discriminações.

A República e suas tentativas de expulsão. Por duas vezes falha. Imita o que deseja expulsar etc. Mas permanece a ideia da eliminação. Exclusão de quê? Todos sabem. Fica a lírica. Ela não espanta a lei. Cordata, fica. Parece que conseguimos, platonicamente sem saber.

Trata-se disso, tipografia. Anterioridade radical, o tipo. Antes de qualquer coisa. Após qualquer coisa. Antes da figura. Antes do conceito. Teatro tipográfico. Sem viver o próprio. A literatura não tem o próprio nem o impróprio lhe é próprio. Indevido? Ela é e não é.

A infidelidade da contradição mítica - a escapar da não contradição da Filosofia e dos seus correlatos: é ou não é. Cenas da vida do bom para nada, a arte, a instabilidade, a vertigem. Tudo detido naquelas duas advertências no platonismo, seu medos: a loucura e a feminização (parentes do literário?). Melhor: a histeria (essa antiga instabilidade do intenso buraco da vida) posso falar assim tão brutalmente do inelutável? "Tudo sai é mesmo de escuros buracos, tirante o que vem do Céu. Eu sei” (ROSA, 1994, p. 856).

Deslocamento intempestivo da mãe-do-corpo. A instabilidade mesma, a escrita literária - "a reconquista da vitalidade e do vigor sentimental. Se fosse possível... Quem o conseguir... Certamente chamarias isso de abertura de caminho" (MANN, 2011, p. 454).

As posturas precisam ser interrogadas, desiquilibradamente. É necessário dar pulos e cambalhotas. D. Quixote mais uma vez, muitas vezes, 
portanto. Para apontar a eficiência que a palavra fim requisita para constituir certos limites pré-definidos, esculpidos por princípios morais. Nada de entregar a arte à dimensão representativa, mediadora, técnica, semiótica e informativa, na qual ela ganha status de vitalismo fatais ou culturalismo frágeis, sacralizando-se à beira da antessala da institucionalização, segundo o simples fato de existir sem portar o saber e o não saber que é.

Nada de sanear a linguagem, por conseguinte. Nada de emendar a ficção. Tudo já está e não está e assim fica, ficcionalizado - todo o resto é política. Vocês sabem: a mimesis é a inscrição do ser-falante. Toda inscrição na linguagem já gira literariamente e tomba. Mesmo aquelas que não apreciamos ou aquelas que não nos qualificam.

Mas se o teatro tipográfico fosse algo ou alguém, seria Sócrates, ou Quixote, ou o literário; ou: nós, que esquecemos de que "há sempre uma qualidade nos contos, que os torna superiores aos grandes romances [...]" (a advertência de Machado de Assis em Várias Histórias). Nossa cultura contista, ensaísta e nada mais e, portanto, muito a atravessar. Pois há uma acepção da autoria, aqui, que de si mesma exige imaginar-se conto, uma acepção de que na ausência disso há impedimento da autoria na tarefa de garantir uma qualidade nos contos, nós.

No rápido: todo Quixote inscrito em Platão (LACOUE-LABARTHE, 2000, p. 123) Toda literatura, minha lucidez de risco. Não há literatura sem a batalha ainda por terminar, contra todos os saneamentos morais da linguagem. Tantos séculos.

Indignidades da arte. A arte é sem lugar - um aqui da aparição da totalidade do mundo. A Literatura é e não é. Impaciência cognitiva. Não há humano que viva sem uma totalidade agora, trabalhos de arte.

Bem antes, bem depois: a verdade é informe. Citar Valery, ou qualquer um outro, é ele e não é ele. "O artista é irmão do criminoso e do demente [...] [há] alguma obra interessante, sem que o autor tivesse aprendido a entender a existência dos celerados e loucos?” (MANN, 2002, p. 333).

As exigências da arte, a literatura. Tarefa enorme - conforme o espírito dos tempos alavanca a desmedida de não mais considerar certas conquistas críticas provenientes da própria arte e, concomitantemente, estabelecem o contraponto de afeição à institucionalizaçáo do discurso de eficiência, sem mais ouvir sobre atribuição crítica, mas ouvindo um bom bocado sobre referência, intra-estética ou extra-estética.

Há que pensar nisso indeterminadamente. Pensar desapropriadamente. Absolutamente - o advérbio de modo aprova a quase indistinçáo entre 
o substantivo e uma terceira pessoa do singular. Não é a mentira e a não mentira toda a ficção, mesmo a verdadeira e a não verdadeira? Mente.

Há de não mais enunciar cordatamente. Há de deixar os fantasmas se apresentarem nas suas vozes. Muitos não acreditam em fantasmas. Toda obra de arte se comporta como um fantasma, como diz Derrida (cito de memória). Há e não há como qualquer fantasma. Acostumemo-nos com a desapropriação.

Há de presumir o saber e o não saber da arte. Dar conta da individualização da escrita e do trabalho de arte. Gesto de insinuação e sugestão de qualificação; o que seria o mesmo que ter atenção redobrada à impugnaçáa da distinçáo entre trabalhos de Arte e a Literatura que a corresponde.

Há de resistir à determinação social-científica e a sua multiplicidade que, por isso mesmo, faz com que a arte verse o vigor do literário: estar sempre para o outro e ser outra "arte". A arte, portanto, nem é discursiva e nem a sua verdade é reflexo de uma época, ou de uma tendência teórica $a$ priori admitida, ou uma definição de estilo e, sim, a insinuação ou sugestão de qualificaçáo do individual em cada nexo vital da arte no trabalho de arte.

\footnotetext{
Mas a linguagem atualizada, libertada sob o signo de individuação até radical, mas ao mesmo tempo consciente dos limites que lhe foram traçados pela língua, das possibilidades que lhe foram abertas pela linguagem, tendo em vista a individuação restante (CELAN, 1999, p. 178).
}

Ora, a arte reage ao período no qual faz sua aparição - sua história figura-se bem na roda de rolimã, roda para trás e desliza para frente. Sugere outras, assim. Um sentido anulado como intenção e posto como desígnio sem acabamento. Ela não se delimita pela época mais chegada, mas por outras diversas de si. Idades de mundo - idades que estáo por dentro de qualquer contemporaneidade. Algo como não entender, ou não acabar de entender arte. Isso diz haver uma indeterminação do entendimento da arte? O enigmático do trabalho de arte é sempre seu estar separado.

Tudo na mentira e não mentira artística; sem coibi-las ou usá-las. Mentira mítica, a lógica da contradição, ou denominemos: perversão fundamental da prática poética; ou da prática da linguagem geral.

A Literatura não tem próprio. Vocês falam os seus nomes. Falam o nome. Falam nomes. Literatura é nome. Mas, não assinala. Bastardia, regência literária. Dramaturgia da desapropriação enunciativa; sem tese, mas com testemunhos. Eis o vasto campo da dramaturgia literária expressa pela 
sua quase inviabilidade, abrangendo a autenticidade do saber e do náo saber da arte: $\mathrm{o}$ assombro - o único fato real porque se apreende pelos sentidos e inteligência concomitantemente - de que a arte existe, de que algo existe como arte, de que o trabalho de arte continua, sendo a arte o testemunho de todas as artes.

Grave força ficcionante da linguagem (como outra coisa, no avesso da potência ficcionante da razão de Kant). Logo, não somos crianças de Sócrates. Sem sujeitos próprios. Linguagem apenas. Teatro tipográfico? Só sei que não diria que nada sei. Só tomo a causa pelo efeito. Mais de D. Quixote, e de Platâo. Um ator; um comediante? A figura do vazio. Acolher tudo e não realizar nada de próprio.

Teatro tipográfico? Sem a lei do próprio, posso dizer, ou podemos dizer: a linguagem. A literária? Ela nas outras artes e estas no desafio dela e nela. Linguagem que vocês acolhem e náo abdicam de ter poder, evitando morar no risco da desinstalaçáo do sujeito.

Seria o sujeito próprio? Ou o próprio do sujeito, como nos ensina Quixote, é o impróprio da leitura? - isso nada tem de próprio. Questóes de páginas-fantasmas? $\mathrm{Ou}$, teremos que viver o segredo dos espectros e as nossas vidas já estão roubadas? Hamlet. O mundo é muito antigo! Temos direito a vingança, assim sendo.

\footnotetext{
$\mathrm{Na}$ grande comédia, a comédia do mundo, aquela para a qual sempre torno, todas as almas quentes ocupam o teatro; todos os homens de gênio encontram-se na plateia. Os primeiros chamam-se loucos; os segundos, que se dedicam a lhes copiar as loucuras, chamam-se sábios (DIDEROT, 1979, p. 361).
}

Instalaçôes tipográficas, eu diria. Errei? Não sei e sei. Os seus textos, seus? Quer dizer: o sujeito nunca coincide consigo mesmo. Literário? Nada pode ser atestado; embora haja testemunho e só da linguagem. Estamos ou somos livres de alguma maneira em nossas literaturas no caminho da arte. Talvez!

A tarefa da arte é derivada do seu saber e não saber, é e não é a Literatura - aproxima-se de lado da linguagem das coisas, formando seus momentos discordantes, numa analogia com a linguagem sem "fins úteis". A tarefa, portanto, que cabe à arte deve ser compreendida como pressuposto do trabalho literário, como ausência de qualquer vestígio teleológico, para lá do abismo das idades, cuja simpatia com o deslocamento não se adapta a qualquer definição de cultura circunscrita por temporalidade delimitada. 
Assim, o saber e o não saber da arte reprova um tipo de noção de cultura que sempre precisa se interrogar sobre o que pode, ela, significar.

A história das artes é uma insistência. Se existir, fica para trás. Só insiste após qualquer futuro. Na pergunta que se faz nos agoras de cada acontecimento - toda história em cada um. Toda história no tempo da história que se afina com tempo da música. Ou seja, tempo interno, não preenchido - a ideia de história no declínio do finito tropeça no infinito, as notas do sofrimento.

A história é um fenômeno linguístico. "A força determinante da forma histórica do tempo não pode ser totalmente aprendida por nenhum acontecimento empírico" (BENJAMIN, 2011, p. 262). Um elemento empiricamente indeterminado é ideia.

Os fantasmas sempre se adiantam no seu atraso. Encenação tipográfica, teatro da escrita. Vaguei. De antemão, ficcionalizado; inscrito. Quixote desinstala todo o platonismo. Instala-se no auge do teatro tipográfico, não seria ele o tipo antes das figuras? Um contra-tipo a Sócrates de Platão? Até porque o que há e não existe, e existe, é a arte ali. Novamente, é e não é?

Há de viver de cicatrizes de nenhuma ferida. A fissura, a abertura. Nos meios de D. Quixote. Fissura é sempre por onde se pode escutar e buscar ver; aprendemos isso com Duchamp. Toda tarefa artística está no ato de requerer um telos numa linguagem que o espectro da cultura não conhece, afirmando seu parentesco com o conhecimento discursivo, cuja diferença se acentua numa quase matemática "distinção entre finito e infinito" (ADORNO, 1993, p. 189).

Eu não sei o que isso estabelece como questôes de fato. $\mathrm{O}$ trivial é: escrever literariamente, ou escrever com ela, é impura perda. Impureza da perda; ou seja: nada se perde tudo se encontra impuro, ficcionalizado.

Só há, portanto, o encontro com o outro. Esse fantasma radical. Isso porque convertemos o enunciador em locutor, o locutor em ator (como diz Lacoue-Labarthe); em personagem, em figura, em pura voz. Esquecemos do tipo.

A Literatura encena a si como um movimento sem defesa num embate dramático com a própria arte, possibilitando recuperar, pelo ato de fazer, o caminho da arte, talvez. Entenda, abertamente, o "relato da viagem", ou seja, o desempenho da leitura plasmado em exercício da escrita.

Tudo a arquivar a loucura, o risco, o não saber e saber; não digo a morte, mas estamos perto. A morte só ganha identidade para o assassino. Louco D. Quixote e assim continua a viver. Muito mais que vivo. Diria: a 
vida; a aventura é teatro tipográfico. Todo ele em Platão. Tantos outros ali e fora dele; ou seja: sem escapatória. $\mathrm{O}$ pensamento nasceu contado. $\mathrm{O}$ contar é o verbo da aurora do pensamento; ouvido e olvidado - a contrapelo, análogo à ideia de Derrida sobre a autonomia pétrea da escrita em face do seu contexto de origem (DERRIDA, 2011).

A loucura, a paixão. Posições em abismo; no risco de haver (verbo de toda a natureza, no reverso do verbo existir), na proximidade da morte. $\mathrm{O}$ sujeito morre por ali. Nasce ali. Na linguagem. Há de contar e interrompido por um comentário. Qualquer um, qualquer outro. Há sempre pausas indevidas e, por isso, há arte.

A presença da arte: ou bem se é a apresentação do presente no haver arte, ou nada de arte; ou bem se é capaz de repensar um pensamento, antropológico ou filosófico, que chega e barra os passos do saber e não saber da arte, fazendo-o se constituir como problema arte no pensamento, ou se tem de deixá-lo passar ao largo, renunciando a ele.

A loucura se imita. A linguagem, a mimesis, a escrita, é coisa dela. $\mathrm{O}$ contrário e o avesso disso também. Num inválido sentido, vou indo. Findo. Aqui toda a minha responsabilidade e admiração por Lacoue-Labarthe. Não estou preocupado com a minha ida agora. Qualifico-me, desqualifico-me na direção de suas ideias. Talvez a direção vá má, como a arte. Estreitamente, mas vai. Vai no aforo inquietante dos textos. Aonde? Donde? Mas com o quê?

Na tipografia? D. Quixote! O literário ainda... talvez!

\footnotetext{
Poesia: pode significar uma mudança de ar. Quem sabe talvez a literatura percorra o caminho - também o caminho da arte - em busca de tal mudança de ar? ... talvez ela consiga aqui diferenciar estranheza de estranheza [...].

Talvez a partir daí o poema seja ele mesmo... e então pode, dessa maneira sem arte, livre da arte, ir pelo seu outro caminho, isto é, o caminho da arte - e sempre ir?

Talvez (CELAN, 1999, p. 176-177).
}

\section{Referências}

ADORNO, Theodor W. Teoria Estética. Lisboa: Ediçóes 70, 1993.

BENJAMIN, Walter. Origem do drama trágico alemáo. Traduçáo João Barrento. Belo Horizonte: Autêntica, 2011.

BORGES, Jorge Luis. Obras Completas. São Paulo: Globo, 1998. 
CELAN, Paul. Cristal. Tradução Cláudia Cavalcanti. São Paulo: Iluminuras, 1999.

CERVANTES, Miguel de. O engenhoso fidalgo D. Quixote da Mancha. Rio de Janeiro: Record, 2005.

CAVELL, Stanley. En busca de lo ordinario. Valência: Frónesis, 2002.

DIDEROT, Denis. Textos Escolhidos - Diderot. Tradução M. de S. Chauí e J. Guinsburg. São Paulo: Abril Cultural, 1979.

DERRIDA, Jaques. A Escritura e a Diferença. Tradução M. B. M. Nizza da Silva, P. L. Lopes e P. de Carvalho. Sáo Paulo: Perspectiva, 2011.

JOYCE, James. Ulisses. Tradução António Houaiss. Rio de Janeiro: Civilização Brasileira, 1996.

LACOUE-LABART, Philippe. A Imitação dos Modernos. Tradução V. de A. Figueiredo e J. C. Pena. Rio de Janeiro: Paz e Terra, 2000.

PESSOA, Fernando. Obra em prosa. Rio de Janeiro: Nova Aguilar, 1983.

MANN, Thomas. Doutor Fausto. Tradução H. Caro. Rio de Janeiro: Nova Fronteira, 2011.

ROSA, Guimarães. Grande Sertáo: Veredas. Rio de Janeiro: Nova Aguilar, 1994.

Marcus Alexandre Motta - marcusalexandremotta@globo.com

Manuscrito recebido em 26 de maio de 2015

e aceito em 26 de junho de 2015. 